\title{
Developing anti-discriminatory education: the impact of specialist training on practitioners and pupils
}

\author{
Carmen Mohamed* \\ Leicestershire Education Authority, UK
}

This article addresses the question as to whether training pre-school practitioners in an approach to antidiscriminatory education can impact on the developing attitudes of young children. This article attempts to analyse the effect of training practitioners in the delivery of an anti-discriminatory curriculum on the developing attitudes of the children they are teaching. This training was carried out with Leicestershire Foundation Stage settings.

\section{Background}

For better or for worse, the whole world can be revolutionised in one generation according to how we deal with the children. (Jebb, 1923, preface)

There has been much talk about equality of opportunity in all walks of life but in education we have to ensure that the rights of all our children are publicly upheld. The trouble is, we all talk about equality of opportunity as if we have a shared understanding of the meaning and have agreed terms of behaviour within an antidiscriminatory framework, which of course we don't. There is a plethora of research (Siraj-Blatchford, 1995; Brown, 1998; Wood, 2000) showing that adults who become part of a child's life between the ages of three and five have a profound effect on the development of a child's values and attitudes towards others. As 'universal nursery education' is phased in by the Government, most children begin state funded education at three. It is essential that highly trained adults nurture this stage of development from an anti-discriminatory stance. It should be embedded in the way adults behave with young children, not a 'bolt on' to the curriculum offered. However, anti-bias in education is not currently a significant part of initial training for practitioners working in Foundation Stage settings (i.e. ages three to five years).

\section{Motivation and driving force}

During the implementation of the Foundation Stage training it became clear that there was reluctance by practitioners to discuss how they put their equal opportunities policy into practice. The majority of practitioners expressed insecurity in fully understanding equality of opportunity and yet research by Siraj-Blatchford (1995) and Rosemary Roberts (2002) tells us it is crucial to the self-esteem and learning experience of all children. Terminology was outdated and visits to both schools and pre-school settings exposed the wide-ranging spectrum of understanding about equal opportunities. We began some work to gather a clearer picture of equality of opportunity in practice across the county of Leicestershire. In spring 2001, practitioners met to discuss how they thought they put the principles from the Curriculum Guidance for the Foundation Stage (Qualifications and Curriculum Authority, 2000, p. 11) into an anti-discriminatory curriculum. The responses referring to the principles of: ‘Celebrating and acknowledging children's differences; promoting non-gender biased activities; 
using children's home experiences and interests as starting points for learning' provided stereotypically sexist or ethnically ignorant images to the children.

The information gathered about the different ways practitioners inspire children and develop their interest in learning revolved around role-play, circle time (children sitting in a circle to take turns in speaking and listening) and alternating a limited range of 'home corners' as role-play areas; none of this related to intrinsically motivating the children by supporting them to become independent learners, exploring different learning styles or giving children the space and time to explore feelings, relationships and responsibilities. The majority of the responses referred to the use of external rewards as a way of ensuring children felt valued and secure, whereas recent research by Rosemary Roberts (2002) about children's emotional well-being suggests that for a child to feel valued and worthwhile, they need to be accepted for who they are. Offering bribes, e.g. stickers, to children to conform to a different norm suggests they are not yet acceptable or worthwhile. Although the practitioners were genuinely concerned about doing the right thing for the children, the responses showed little knowledge or understanding of the real impact of the way they were presenting diversity to children. All of the practitioners welcomed the chance to discuss the issues and share their ideas together. This initially reassured them that they were all doing the same thing; therefore they must be on the right lines. The ideas presented us with a picture of the level of understanding and practice that occurred throughout the county and formed the baseline from which I developed the training package. Our aim was to increase levels of awareness and effect change in practice, which would ultimately impact on the children's developing attitudes and rights. My main concern was that it was going to be difficult in the short term to evaluate the impact on children's attitudes to inclusion and equality. There is a need for a more long term, focused, committed approach to raising awareness at all levels.

Attempting this kind of work challenges our own beliefs, values and attitudes. Scrutinising the way we approach situations and our attitudes to other people will develop our respect for ourselves. It could be painful at times to discuss some issues as a team but it will also be supportive and rewarding if approached sensitively. Although it is unlikely that blatant and intentional discrimination occurs in educational settings, many of the attitudes developed by young children are as a consequence of messages received through body language or ignorance of issues, rather than openness and challenge from the adults around them. It is important that professional development affords practitioners the opportunity to reflect on how discrimination occurs. In this way an attempt can be made to move beyond a simplistic view of children as innocent and harmless, towards discussion to address issues of race, class, disability, ethnicity, sexuality and gender. Siraj-Blatchford (1995, p. 67) argues: 'Children need to be educated to deal confidently and fairly with one another and with others in an unjust society. Listening, understanding, participating and accepting differences are fundamental attributes'. Adults must be constantly aware of discriminatory language and practice by all those involved in the setting, and be ready to challenge it. A strategy agreed by the whole staff is the most effective and supportive way of achieving this.

\section{How do we effect change?}

So, how can practitioners support children to develop attitudes and an identity in which they value themselves and others as equal but different? This is the challenge set by the British National Curriculum 2000, the Foundation Stage Curriculum Guidance for 3 - 5 year-olds in Britain and the Office for Standards in Education 
(Ofsted) Inspections. The range of understanding in the Foundation Stage settings highlighted the need for fully comprehensive training in this vital area. Around the same time, training for Foundation Stage practitioners had been set as a target for all Local Authority Early Years and Childcare Development Partnerships (a local partnership group set up within Local Authorities to develop the quantity and quality of childcare and early education in each regional locality). All pre-school settings were required to identify and train someone to establish and implement an equal opportunities strategy (target 21). There was no indication about the form this training would take, who would deliver it, nor whether there were guidelines for monitoring and evaluating the strategies for future development. The training of practitioners would be the single most important factor in developing a strategy to implement equality and justice for all. Effective learning development is as much about the way experiences are offered to young children as it is about the activities offered. All children have the right to equal access and opportunity of experiences (not necessarily the same); this does not happen by chance, it has to be carefully planned and effectively monitored. Children have the right to learn that people must all be valued equally. It cannot be left to chance that practitioners will challenge their own thinking and develop the understanding of their staff; it would be all too easy to take the comfortable way forward and continue in the belief that we already deliver the ideal.

The emphasis for training had to be on changing attitudes and practice through understanding why people think and act the way they do and where their level of understanding about equality lies. There must be awareness that all adults will have their own cultural beliefs and values which may not be in line with government thinking for an inclusive education system. In attempting to support the positive development of children in the area of identity and attitudes to others, there is a risk that the cultural beliefs of those significant adults are brought into question. This poses problems specifically for the child where conflicting information is offered by the state, their playgroup practitioners and their parents. Trainers had to carefully and sensitively challenge the cultural beliefs and values of the practitioners delivering the curriculum.

\section{The training programme}

Before the training began, practitioners were asked to fill in a questionnaire relating to their knowledge and understanding of anti-discriminatory education and the type of activities they offered to children to ensure equality and inclusion. This was to enable us to determine the impact the training would have on their thinking and practice. At the first training session the focus was on raising awareness of an anti-discriminatory approach to the curriculum. It was important to share recent research in a way that was relevant and accessible to the practitioners. Participants were guided through the reasons for developing a strategy for this work within their settings and then offered suggestions to support them in carrying out their own needs analysis. They were asked to carry out an audit in terms of staff awareness, quality and use of resources and children's attitudes and knowledge of differences between people.

We began with the acknowledgment that children develop their sense of identity from the acceptance and attitudes of others towards them; therefore everyone working within an early years' setting must scrutinise their curriculum and their attitudes and vocabulary. Young children learn from everything that they experience in their environment, everything that happens to them. If a child's environment is sexist or racist they will learn this as something that is acceptable to the significant adults around and develop these attitudes as the norm. We need to give children the relevant experiences through images, activities and attitudes which allow them to 
explore different ways of living and be able to deal with prejudice when it arises. Unless these attitudes and values are explored with the support of adults and challenged where necessary from a young age, children will be as unsure as adults currently are to challenge injustice as they grow. Children need opportunities to form positive relationships in a setting which recognises the adverse effect of racism and religious, gender and disability discrimination in influencing children's developing sense of themselves and others. The Qualifications and Curriculum Authority (2000, p. 17) state that 'children have the right of access to adults who act as guides, exemplars and supporters in developing relationships and challenging bias and who feel confident about all aspects of providing an anti-bias setting'.

The second of the three training sessions was organised for three months later when practitioners were asked to return with their audit and priorities for action. They were encouraged to share their points for action and were supported by experts in different fields to agree a way forward. The training focused on challenging discrimination. At the end of the session a second questionnaire sought information about the impact of the training on their thinking and practice. The questionnaire was analysed to give a picture of the shift in attitudes and understanding of practitioners and how they perceived their role in having an impact on the development of young children's knowledge of equality. From the responses it was possible to draw conclusions about the likelihood of the impact of training on practice and therefore on the children's understanding and attitudes.

\section{Outcomes from session one}

Before the training programme began only $13 \%$ of the responses to questionnaire one indicated an understanding of the principles of anti-bias education and were ready to be proactive in targeting possible discrimination. Almost half (45\%) of the responses were able to show an awareness of the issues involved in anti-discriminatory practice although they offered naive if not discriminatory responses. On the whole they were trying to get things right but were unsure of how to go about this. This group was the most promising target group for effecting change. We felt less positive about the fact that $42 \%$ of the responses were fairly negative to a perceived need, believing that 'we don't have a problem here', 'it is for the parents to tackle not pre-school leaders'. All of these responses believed that children could not be prejudiced. When asked how they would tackle discrimination, they wrote: 'It's not our place to educate parents', 'parents have their views and we do not have to agree'. Jane Lane (1998, p. 54) would argue to the contrary: Children are not born with attitudes and values, they learn them. They take them from what they hear and see around them - from adults and other children, from books, dolls, toys, posters and the media. Sometimes, they pick up negative views about people based on such things as their skin colour, language, culture or way of life.

The responses shared reflected our expectation: the proportion of responses in each 'cluster' was not a great surprise. We had been prepared for a large proportion of well meaning if ill-informed and sometimes negative responses. Our aim was to challenge the more negative participants, making them aware that they had a legal and moral responsibility to separate their personal prejudices from their professional practice. Early years settings must pay regard to the Race Discrimination and Sex Discrimination Acts and although we know that laws cannot change people's attitudes, we can use them to convince people of the need to change their practice and to help them to feel more confident when tackling discrimination (Lane, 1998). Almost half of those prepared to respond to the questionnaire were trying to offer an unbiased curriculum, sharing with the children different ways of life. However, the impact of the way these differences are presented to children was not considered. It seemed likely that once this group had been offered more appropriate alternatives they would be 
able to change their practice sufficiently to have a positive impact on the developing attitudes of the children in their care. We were hopeful that by sharing the current research about children's developing attitudes and their rights, the middle cluster of participants would welcome being better informed about good practice and would readily change the way they explored diversity through their curriculum.

During the training it became obvious that the most difficult issue for many practitioners to overcome was that of gender stereotyping. Although practitioners were comfortable discussing issues raised about disability and ethnicity, they were unmoving in their attitude to their part in the development of gender-specific roles. Many practitioners shared experiences of how the children choose to play with certain toys and that they felt it was wrong to try and make them play with toys they hadn't chosen themselves. It was difficult for them to accept that the children were self-limiting due to the pressures of sexism already in place in the pre-school. As a group, the vast majority of participants were women; this may be a shared cultural attitude and belief which affects them personally. They were willing to accept the need to change their understanding of how to present different lifestyles to their own, but when their own came into question their views were too entrenched for them to see a need for change.

Children's sense of identity is a fundamental aspect of their development; it is not just about discussing the differences between individuals or groups; identity is built through interactions. By providing an opportunity to live out inclusive attitudes and values, early education settings can be a place where children learn about human rights. If children grow up from the onset of education knowing that everyone has equal value and rights then they will be more likely to challenge any discriminatory practice, rather than the situation we have at present where, as adults, we are struggling to become aware of our own discriminatory practice let alone challenge it in others. The single main concern for practitioners was that they were given the latest information about correct terminology for referring to different groups. They felt that language had moved on and they weren't in a position to find out about it until they offended someone. Many practitioners said that they were surprised that they were saying the wrong thing and were keen to put that right. Changing terminology was a step in the right direction for us.

The information collated from the session one course evaluations was on the whole positive and proactive. We appeared to have had some success at affecting the attitudes, knowledge and understanding of the practitioners. Many of the participating settings requested further information, materials and training and acknowledged the need to find out more about anti-bias education. These initial findings gave a promising view as to how the training might affect the practitioners and therefore the children. The practitioners were now more aware of messages given in books and the appropriateness of resources and ready to observe adult and child behaviour with knowledge of discriminatory activity.

\section{Outcomes from session two}

After the second session of training, $83 \%$ of the responses informed us they were confident that their own awareness of the issues had been raised and that the training had had an impact on their attitudes and on their practice. More than half (53\%) of responses indicated that they had already made small adjustments to their practice, mostly by increasing the provision of resources. Although some said that their attitudes and knowledge had been moved on too, they were aware of the need for further training and were actively seeking out further support. Many of them referred to the training as 'eye opening' saying that it 'provoked stimulating 
conversations' and that the impact was 'hopefully considerable' but were still taking in the implications of their own attitudes for the children. Many respondents were much more comfortable after the second training session; this may have been due to the chance to debate further the issues in a more relaxed situation, their staff meeting, but it could also be attributed to the chance to observe some of the issues discussed in action in their preschool. On the whole they were aware of the need for and open to change though they did not fully understand what they had to do to make the changes. They were willing if a little daunted after the training. Seventeen per cent of the responses stated that the training had had little or no impact on their attitudes or practice 'as they were already doing that'. Most of these responses felt that the training 'reinforced good practice' and 'made them more aware'. Only one said that 'the staff would not gain from the training'. A few responses were negative in their outlook believing that we were 'making an issue out of something that should not be an issue'. Others said that they had told the staff about the training but that there was already too much paperwork, a lack of resources or that they 'felt more insecure about what they could say' after the training. A number of practitioners told us that 'Ofsted had been and told them that they just needed more pictures and books about special needs', which indicated that although they had received the same training programme as other participants, they would do nothing until Ofsted told them to. This advice was in direct conflict with the advice received during the training, which promoted diversity as the norm, not as a focus of difference.

\section{Conclusion}

The aim of the curriculum guidance will 'most readily be achieved where skilled and knowledgeable staff hold high expectations of all children, not limited by stereotyped views about class, cultural background, sex or special educational needs' (Brown, 1998, p. 3). Adults must be constantly aware of discriminatory language and practice by all those involved in the setting, and be ready to challenge it. Where children bring discriminatory attitudes and language into our settings, the adults need to be properly prepared and equipped to effectively and sensitively challenge, in order that no child is left feeling confused, bewildered and hurt. Adults need to be aware that so many stereotypes have become so deeply ingrained that they have become part of the English language. They also need to be prepared to accept challenge where appropriate.

The results of the questionnaires are inconclusive in their impact on the children at this stage this would require a long-term study, following a group of young children in developing their attitudes. However, the responses give cause for both celebration and hope as a vast number of the respondents (83\%) had taken on board the issues raised and subsequently begun to make changes. Given the number of participants prepared to discuss their enlightenment of how to offer diversity to children within their curriculum, there was every hope that children would be given fewer stereotypical images of people in other countries and that the tourist curriculum of 'doing Diwali and Chinese New Year' might be developed into a more relevant and diverse curriculum. Interestingly, only $41 \%$ of participants were willing to fill out questionnaire one before the training, whereas $83 \%$ were willing after session two. This possibly indicates levels of insecurity about the subject before the training. Fifty-three per cent of participants in the training programme indicated that they were ready and willing to respond proactively to the suggestions offered.

Many told us that they would welcome training for their full staff team from an external adviser. They felt that this would support them in making changes whilst taking the burden off them. Whilst it would be impractical to 
offer in-service training to each of the 350 funded pre-school settings, each of them could request further support from the qualified teacher involved with the setting.

We were anxious that the training should have a lasting effect. By offering small manageable steps with built-in support, we hoped to make an impression on practice to the benefit of our youngest children. The second training session has been followed up by a team of teachers trained to support pre-school settings in the implementation of their strategy and in using the 'Leicestershire Anti-Bias Framework' effectively. In the final session of the training programme, settings have been supported in monitoring and evaluating their success at implementing the strategy. Continued support will, it is believed, encourage practitioners to keep this strategy uppermost in their minds.

The impact of the training has been extremely successful in raising levels of awareness and encouraging the majority of practitioners to make effective changes to the delivery of an anti-discriminatory curriculum. In time this will have a positive impact on the developing attitudes and rights of the children in our care. The three part programme was devised to offer as much support and guidance as possible. It has been successful in encouraging practitioners to be thinking about the changes as a long-term strategy. The challenge of ending discrimination of all kinds is a responsibility of all educational practitioners as guardians of our children.

\section{References}

Brown, B. (1998) Unlearning discrimination in the early years (Stoke-on-Trent, Trentham Books).

Jebb, E. (1923) Teachers handbook: teaching the UN Convention on the Rights of the Child (Oxford, Save the Children Fund (SCF)/United Nations Children's Fund (UNICEF) Education Departments CoProduction, 1990).

Lane, J. (1998) Action for racial equality in the early years (Ipswich, National Early Years Network $[\mathrm{NEYN}])$.

Qualifications and Curriculum Authority (2000) Curriculum guidance for the Foundation stage (London, QCA) (draft).

Roberts, R. (2002) Self-esteem and early learning (London, Paul Chapman Publishing).

Siraj-Blatchford, I. (1995) The early years: laying foundations for racial equality (Stoke-on-Trent, Trentham Books).

Wood, L. (2000) Teaching through play (Cambridge, Chris Kington Publishing). 